\title{
Acute lymphopenia, stress, and plasma cortisol
}

\author{
L. H. J. RAMAEKERS, P. M. THEUNISSEN, and K. WENT \\ From the Department of Paediatrics, St. Annadal Hospital, Maastricht, the Netherlands
}

\begin{abstract}
Ramaekers, L. H. J., Theunissen, P. M., and Went, K. (1975). Archives of Disease in Childhood, 50, 555. Acute lymphopenia, stress, and plasma cortisol. Plasma cortisol levels were determined in 51 children on admission to hospital for a variety of acute illnesses which were associated with a lymphopenia, and again when the lymphocyte count had returned to normal. The ratio cortisol level/lymphocyte count was much higher in the acute phase of the illness than later when the lymphocyte count had returned to normal. It is concluded that the lymphocyte count is a useful means of detecting an acute stress condition, and the time of return of normal plasma cortisol levels.
\end{abstract}

Reduction in circulating lymphocytes in children has rarely been accorded much diagnostic significance. In adults, Zacharski and Linman (1971) analysed 178 cases with 7350 leucocyte counts which showed both a relative and an absolute lymphopenia and noted a relation between lymphopenia and malignancy, but the significance of acute transitory lymphopenia was not evaluated. Transitory lymphopenia occurs in many acute disorders at all ages. These changes are more impressive in children than in adults because the absolute and relative numbers of circulating lymphocytes in these two age groups are normally very different; from 60 per 100 white cells in infants decreasing to adult levels of 30 per 100 white cells at puberty.

The characteristic haematological responses following acute stress or corticosteroid medication, namely neutrophilia, lymphopenia, and eosinopenia (Selye, 1950) are well known. Such haematological changes following stress depend on an adequate discharge of ACTH and corticoid hormone (Dougherty and Frank, 1953). Numerous rereports and reviews (Dougherty and White, 1944, 1945, 1947; Dougherty, 1952) concern the fact that there is an inverse relation between plasma ACTH level and lymphatic tissue mass, including that of the lymphocytes of peripheral blood. The question arises whether the acute, transitory lymphopenia (absolute and relative), so frequently seen in paediatric patients, is a useful sign of acute systemic stress as measured by the plasma cortisol levels.

The purpose of this study was therefore to

Received 2 December 1974. investigate the relation between acute lymphopenia and plasma cortisol levels, and to evaluate the usefulness of routine lymphocyte counts in clinical paediatrics. No such study has been made in children, although Frank and Dougherty (1953) described the lymphocytic response in 10 normal human adults given ACTH, and correlated blood cortisol levels with lymphocyte counts in various conditions, such as infectious mononucleosis, tuberculosis, and advanced cirrhosis.

\section{Materials and methods}

The children included in this study were those admitted to the paediatric department showing a relative lymphopenia (i.e. $>50 \%$ reduction of the mean normal values) irrespective of the total leucocyte count. By collating the data of Nelson, Vaughan, and McKay (1969) and Smith (1972) we took the following mean values for lymphocytes as a percentage of total white blood cells: cord blood $30 \%$, at 2 weeks $50 \%, 3-6$ months $60 \%, 2-4$ years $50 \%$, 6 years $45 \%$, gradually decreasing to $30 \%$ at puberty. Figures on standard deviations are not available.

Of 51 patients 23 were male and 28 female, ranging in age from one newborn to 13 years. Cases in which the lymphopenia was due to known causes such as cytotoxic drugs, corticosteroids, irradiation, or systemic disease were excluded. In several cases a definite diagnosis was not available on admission and in this respect the cases were unselected.

Total leucocyte counts were obtained in duplicate and 200 cell differential counts were carried out on May-Grünwald-Giemsa stained peripheral blood smears. Within one hour of the blood count determination, blood was withdrawn by venepuncture and the cortisol levels determined by the method of Stahl, Hertling, and Knappe (1963). The exact time was noted. There- 
after total leucocyte and differential counts were done every second day, and at the same time of day in order to eliminate the influence of the normal diurnal variations in cortisol levels and lymphocyte counts (Elmadjian and Pincus, 1946). The cortisol level was again determined as soon as the lymphocytes had risen to levels normal for the age of the child concerned. Daily lymphocyte counts and cortisol level determinations were carried out in the same way in one case of acute viral disease of undetermined type.

\section{Results}

Major diagnoses are listed in 4 groups in Table I. The number of days elapsing between the lymphopenic state on admission and the return to normal values is shown in Table II.

Fig. 1-3 show the leucocyte counts and the number of lymphocytes, expressed both in absolute terms and as a percentage of total leucocytes on admission (represented by 'stress') and on reaching

\section{TABLE I}

\section{Clinical diagnosis in 51 patients}

\begin{tabular}{lr}
\hline I. Acute virus-infections & 1 \\
Laryngitis & 5 \\
Bronchitis & 1 \\
Meningitis & 2 \\
Enterocolitis & 1 \\
Mumps & 1 \\
Measles & 1 \\
Herpetic stomatitis & 1 \\
Erythema infectiosum & 1 \\
Undetermined & 14
\end{tabular}

II. Acute bacterial infections

Septicaemia

Osteomyelitis

Meningitis

Pyelonephritis

Tonsillitis

Perforated appendix

Bronchopneumonia

Lymphadenitis

Total

19

III. Acute trauma

Normal birth (neonate)

Head injury

Renal contusion

Tibial fracture

Drowning

Skin burn $(25 \%)$

Total

IV. Miscellaneous

Febrile convulsions

Rheumatic fever

Streptococcal nephritis

Encephalopathy

Acute ataxia

Acute haemorrhage (dental extraction)

Total

\section{4}

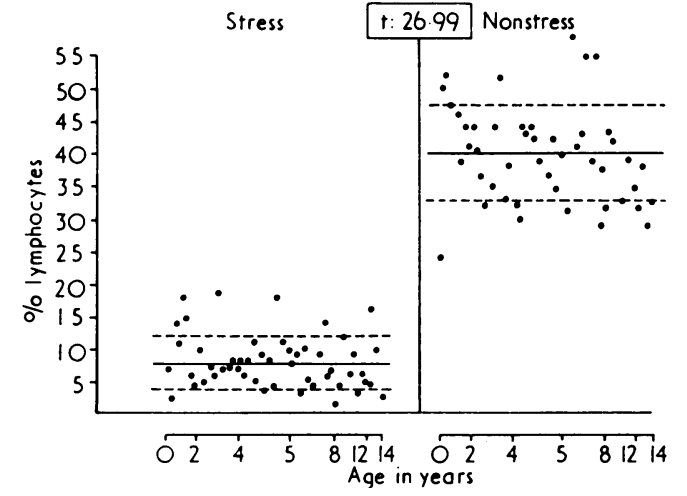

FIG. 2.-Lymphocyte counts as percentage of total $W B C$ on admission (stress) and recovery (nonstress).

$$
\text { mean; - - - } 1 \text { SD. }
$$

normal control values (represented by 'nonstress'). The patients are plotted according to age. Fig. 4 similarly shows plasma cortisol levels in stress and nonstress conditions. The ratio between the cortisol level and the lymphocyte count in stress and nonstress conditions is shown in Fig. 5. 


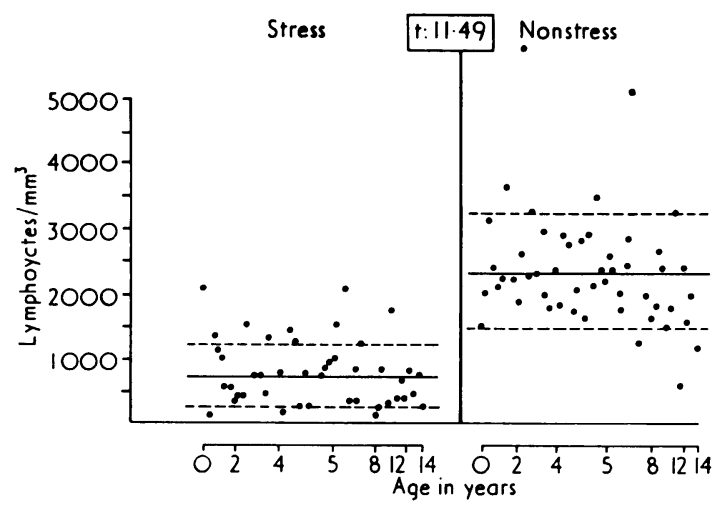

FIG. 3.-Lymphocyte counts $/ \mathrm{mm}^{3}$ on admission (stress) and recovery (nonstress). - mean; - - 1 SD.

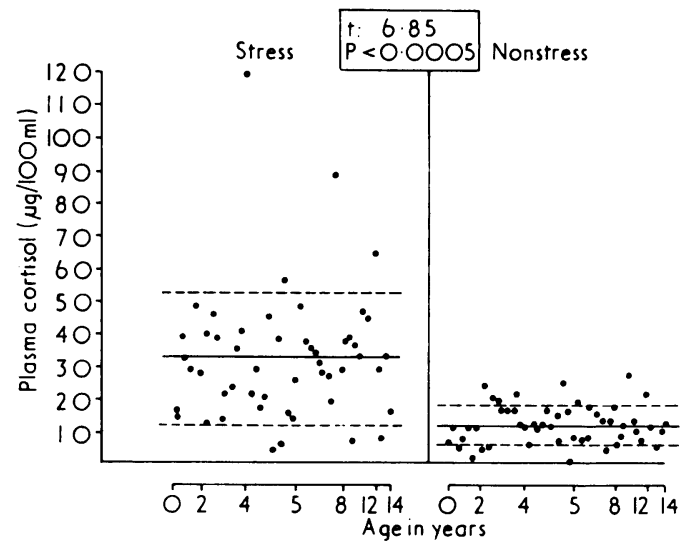

FIG. 4.-Plasma cortisol levels on admission (stress) and recovery (nonstress). - mean; - - $1 S D$.

Fig. 6 shows the daily observations on leucocyte count, absolute and percentage lymphocyte values, plasma cortisol levels, and temperature in the patient suffering from an acute viral disease of short duration.

\section{Discussion}

The results show an obvious difference $(\mathrm{P}<$ 0.0005 ) between the stress and the nonstress values of the ratio plasma cortisol level/lymphocyte count. A low lymphocyte count is associated with a high plasma cortisol level, while the rise in lymphocytes to normal levels coincides with a return to normal plasma cortisol levels. Almost all children proved to have had an acute disorder of some kind (Table I), with a history of short duration (usually

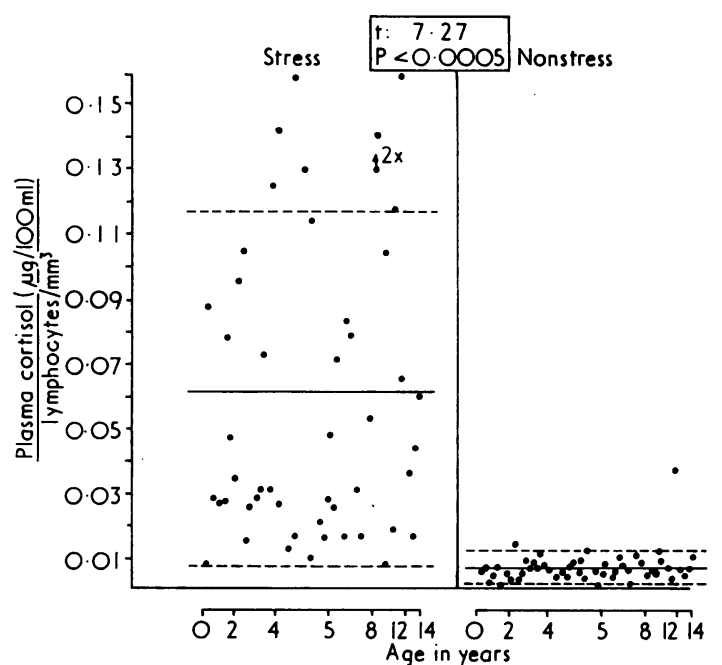

FIG. 5.-Ratio of plasma cortisol to absolute lymphocytes under stress and nonstress situations. - mean; $-\longrightarrow 1 S D$.

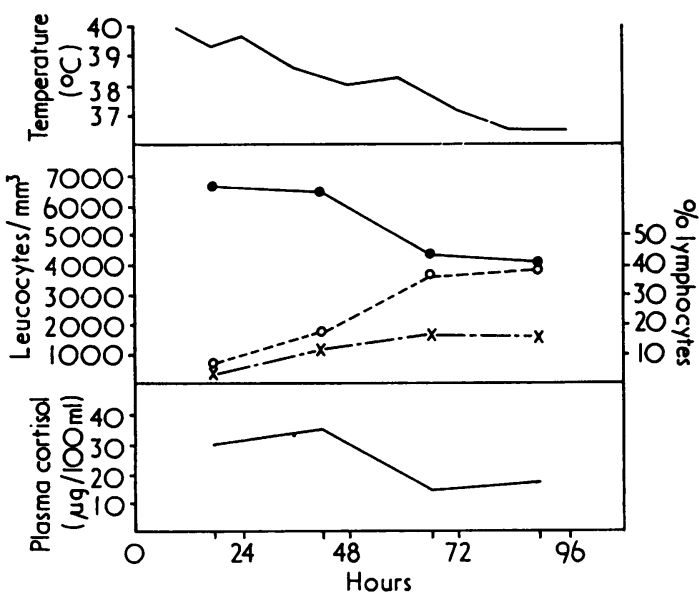

Fig. 6.-Case of acute viral infection. Daily (at same time) observations on temperature, total leucocytes ( $)$, absolute $(X)$ and relative $(\circ)$ lymphocyte counts, and plasma cortisol level.

less than 24 hours). The stresses varied widely, including acute viral infections, acute bacterial infections, and acute traumatic conditions among others. No correlation was found between the clinical severity of the type of stress and the degree of lymphopenia or the level of cortisol. The stress response as measured by the cortisol levels seems to be the same in self-limiting viral infections as in severe bacterial infections. 
Although in an acute stress state leucocytosis was frequent, there were many cases with normal or low leucocyte values, no doubt due to effects of the individual stress. Concomitant with the lymphopenia of the acute phase, there was virtual absence of eosinophils, which usually reappeared along with the rise in lymphocytes. A similar observation was made by Thorn et al. (1953). In 31 cases (61\%) the lymphocyte count returned to normal within 10 days, and in 43 cases (84\%) within 15 days (Table II). The return to a normal lymphocyte count took longer than 16 days in the case of burns and in severe bacterial infections. No differences were found according to sex or age, and even the neonate seems to react in a similar way to the stress of normal parturition, as evidenced by the fall in lymphocytes (Xanthou, 1970).

Although Fig. 4 shows that there was some overlap in cortisol levels in stress and nonstress conditions, only 6 cases showed little or no fall between the first and second samplings. In one of these (as was discovered later) the patient had already received steroid medication to relieve laryngeal obstruction, and suppression of his adrenal response to stress may have occurred. The other 5 cases included acute lymphadenitis, 2 acute streptococcal nephritis, 1 convulsions with mental retardation, and 1 bleeding after dental extraction.

We conclude that in clinical paediatrics more attention should be paid to the absolute and percentage lymphocyte count than is usually done, since lymphopenia can indicate a stress situation and is associated with a high plasma cortisol level. Unexplained lymphopenia should therefore alert the physician to the possibility of an underlying acute stress situation. Furthermore, in following the progress of acutely ill children, the lymphocyte counts can probably be used as a guide to determine the time when the patient returns to a 'nonstressed state'.

Thanks are due to Dr. C. Mink, biochemist, Dr. T. Oei, Department of Physical Medicine, St. Annadal Hospital, and to Mr. H. Caberg and Mrs. G. Saat for preparing the manuscript.

\section{REFERENCES}

Dougherty, T. F. (1952). Effect of hormones on lymphatic tissue. Physiological Reviews, 32, 379.

Dougherty, T. F., and Frank, J. A. (1953). The quantitative and qualitative responses of blood lymphocytes to stress stimuli. fournal of Laboratory, and Clinical Medicine, 42, 530.

Dougherty, T. F., and White, A. (1944). Influence of hormones on lymphoid tissue structure and function. Endocrinology, 35, 1.

Dougherty, T. F., and White, A. (1945). Functional alterations in lymphoid tissue induced by adrenal cortical secretion. American Fournal of Anatomy, 77, 81.

Dougherty, T. F., and White, A. (1947). An evaluation of alterations produced in lymphoid tissue by pituitary-adrenal cortical secretion. Fournal of Laboratory and Clinical Medicine, 32, 584

Elmadjian, F., and Pincus, G. (1946). A study of the diurnal variations in circulating lymphocytes in normal and psychotic subjects. Fournal of Clinical Endocrinology, 6, 287.

Frank, J. A., and Dougherty, T. F. (1953). The assessment of stress in human subjects by means of quantitative and qualitative changes of blood lymphocytes. Fournal of Laboratory and Clinical Medicine, 42, 538.

Nelson, W. E., Vaughan, V. C., and McKay, R. J. (1969). Textbook of Pediatrics, 9th ed. Saunders, Philadelphia.

Selye, H. (1950). Physiology and Pathology of Exposure to Stress, 1st ed., p. 404. Acta Medical Publishers, Montreal.

Smith, C. H. (1972). Blood Diseases of Infancy and Childhood, 3rd ed. Mosby, St. Louis.

Stahl, F., Hertling, L., and Knappe, G. (1963). Eine einfache fluorometrische Methode zue Routinbestimmung von Corticosteroïden in Plasma. Acta Biologica et Medica Germanica, $10,480$.

Thorn, G. W., Jenkins, D., Laidlaw, J. C., Goetz, F. C., Dingman, J. F., Arons, W. L., Streeten, D. H. P., and McCracken, B. H. (1953). Pharmacologic aspects of adrenocortical steroids and ACTH in man. New England fournal of Medicine, 248, 323.

Xanthou, M. (1970). Leucocyte blood picture in healthy full-term and premature babies during neonatal period. Archives of Disease in Childhood, 45, 242.

Zacharski, L. R., and Linman, J. W. (1971). Lymphocytopenia : its causes and significance. Mayo Clinic Proceedings, 46, 168.

Correspondence to Dr. L. H. J. Ramaekers, Department of Paediatrics, Ziekenhuis St. Annadal, Maastricht, The Netherlands. 